\title{
Имплантация ионов кремния в сапфир: малые дозы
}

\author{
(C) Н.Е. Белова, С.Г. Шемардов, С.С. Фанченко, Е.А. Головкова, О.А. Кондратьев \\ Национальный исследовательский центр „Курчатовский институт“, \\ 123182 Москва, Россия \\ E-mail: belova.nina@inbox.ru
}

Поступила в Редакцию 8 апреля 2020 г.

В окончательной редакции 16 апреля 2020 г.

Принята к публикации 16 апреля 2020 г.

В результате ионной имплантации ионов кремния в сапфир и последующего высокотемпературного отжига в приповерхностной области сапфира наблюдаются преципитаты кремния и алюмосиликатов. Рентгеновские измерения методом сканирования обратного пространства показали наличие напряжения сжатия с деформацией $-0.12 \%$ в нормальном направлении и напряжения растяжения с деформацией $0.2 \%$ в $R$-плоскости в этой области, что уменьшает несоответствие параметра решетки по отношению к кремнию (100) и может привести к повышению кристаллического качества эпитаксиальных пленок кремния, выращенных на таких модифицированных сапфировых подложках.

Ключевые слова: ионная имплантация, сапфир, наночастицы, преципитаты, рентгеновская дифрактометрия, рефлектометрия.

DOI: 10.21883/FTP.2020.08.49648.9405

\section{1. Введение}

Специальная микроэлектроника в основном использует структуры кремний-на-изоляторе дефисы (КНИ), позволяющие решать проблемы быстродействия, радиационной стойкости, повышенных температур эксплуатации и т.д. Подложки КНИ в России главным образом представлены двумя разновидностями (Smart Cut и SIMOX), полученными на кремниевых подложках, закупаемых за рубежом [1,2]. Российская промышленность по-прежнему представлена структурами кремнийна-сапфире (КНС), имеющими довольно низкое качество эпитаксиального кремниевого слоя [3]. Кардинальное уменьшение дефектности кремниевого слоя возможно при использовании метода твердофазной рекристаллизации [4], а радиационная стойкость микросхем может быть увеличена созданием вблизи границы раздела кремний-сапфир центров захвата/рекомбинации носителей заряда. В качестве таковых могут использоваться газовые включения или кремниевые преципитаты. Авторами показана возможность получения гелиевых микропор в сапфировой подложке КНС структуры при имплантации ионов гелия и последующем высокотемпературном отжиге [5-8]. Вместе с рядом достоинств (одним из которых является уменьшение упругих напряжений в слое, вызванных разностью параметров решетки кремния и сапфира [6]) данный способ обладает и рядом ограничений, одним из которых является блистеринг, наблюдаемый при превышении критической концентрации гелия после ионной имплантации при дальнейшем высокотемпературном отжиге [5]. Создание рекомбинационного слоя из кремниевых преципитатов в сапфировой подложке $\left(\mathrm{Al}_{2} \mathrm{O}_{3}\right)$ не должно приводить к подобным ограничениям, и теоретически возможно получение близкого к стехиометрии кремниевого слоя. В данной работе представлены результаты исследований приповерхностного слоя сапфировой подложки с ориентацией (11ㅣ) после имплантации кремниевых ионов в сапфир и отжига.

\section{2. Оборудование и методики эксперимента}

Имплантация ионов кремния с энергией 70 кэВ проводилась в сапфировые подложки с ориентацией (1102) $(R$-плоскость $)$ на установке ИЛУ-100 [9]. Доза имплантации $2 \cdot 10^{16} \mathrm{~cm}^{-2}$ выбиралась из условия минимума радиационных дефектов при температуре имплантации $\sim 100^{\circ} \mathrm{C}$. После имплантации образцы отжигались при $1100^{\circ} \mathrm{C}$ в течение 1 ч. Средний проецированный расчетный пробег ионов $\mathrm{Si}^{+}$в $\mathrm{Al}_{2} \mathrm{O}_{3}$ по программе TRIM составляет $\sim 60$ нм.

Количество кремния в образцах до и после отжига определялось рентгеновским флуоресцентным методом на рентгеноспектральном анализаторе Clever B-23 с погрешностью определения количественного состава $\sim 1 \%$.

Дифракционные измерения отожженных образцов для обнаружения и идентификации преципитатов проводились на дифрактометрических установках ДРОН-3М и дифрактометре Bruker AXS D8 Advance по схеме Брэгга-Брентано (горизонтальное расположение образца и угловое перемещение трубки и детектора) с использованием линии излучения меди $\mathrm{Cu} K_{\alpha}$.

Исследование влияния преципитатов на приповерхностные слои сапфира изучалось на лабораторном рентгеновском дифрактометре „Rigaku Smartlab“ с вращающимся анодом и с использованием характеристического излучения меди $\mathrm{Cu} K_{\alpha 1}$ (длина волны $\lambda=1.54056 \AA$, энергия излучения 8.048 кэВ). Рентгенооптическая схема эксперимента состояла из фокусирующего параболического зеркала Гёбеля в схеме Бартельса, двукратного 
монохроматора Ge 220, системы коллимирующих щелей и точечного сцинтилляционного детектора. Образец был установлен на горизонтальный гониометр $\theta-\theta$. Высокая коллимация и светосила установки позволили по дифрактометрическим измерениям методом RSM (измерения в обратном пространстве) наблюдать изменения параметров решетки сапфира в направлении, перпендикулярном поверхности образцов, а также исследовать приповерхностный градиент плотности образцов методом полного внешнего отражения (ПВО).

\section{3. Экспериментальные результаты}

Рентгеновский флуоресцентный анализ (рис. 1), проведенный для образцов сразу после имплантации и после последующего высокотемпературного отжига в течение 1 ч при температуре $1100^{\circ} \mathrm{C}$, показал совпадение интегральных интенсивностей пиков кремния $K_{\alpha 1} \mathrm{c}$ точностью $\sim 2 \%$, что для столь малых доз является хорошим результатом. Таким образом, подтверждено, что при высокотемпературном отжиге кремний не покидает сапфир.

Дифрактометрические кривые для образцов снимались на дифрактометре Bruker AXS D8 Advance по схеме Брэгга-Брентано с графитовым монохроматором перед детектором. На рис. 2 приведена экспериментальная дифрактограмма с интенсивностью для преципитатного слоя, не нормированной на изменение объема взаимодействия при увеличении угла для тонкого слоя. В районе углов $2 \theta=40,70,89^{\circ}$ наблюдаются наноразмерные образования. Проведенные эксперименты показали, что они имеют четкую угловую корреляцию с сапфировой матрицей - при отклонении $R$-плоскости от плоскости рассеяния преципитатные пики не регистрируются.

При угловой настройке в районе $70^{\circ}$ был выделен пик отражения (400) Si на дифрактометре ДРОН-3М с шириной кривой на полувысоте $\sim 3^{\circ}$ и угловым положением

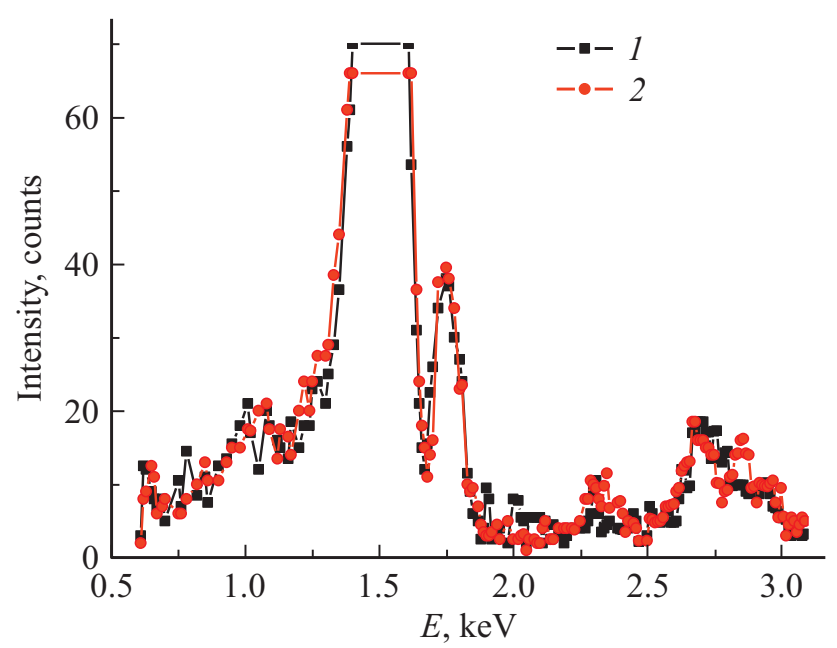

Рис. 1. Рентгеновские флуоресцентные кривые образцов: 1 - после имплантации, 2 - в результате последующего отжига.

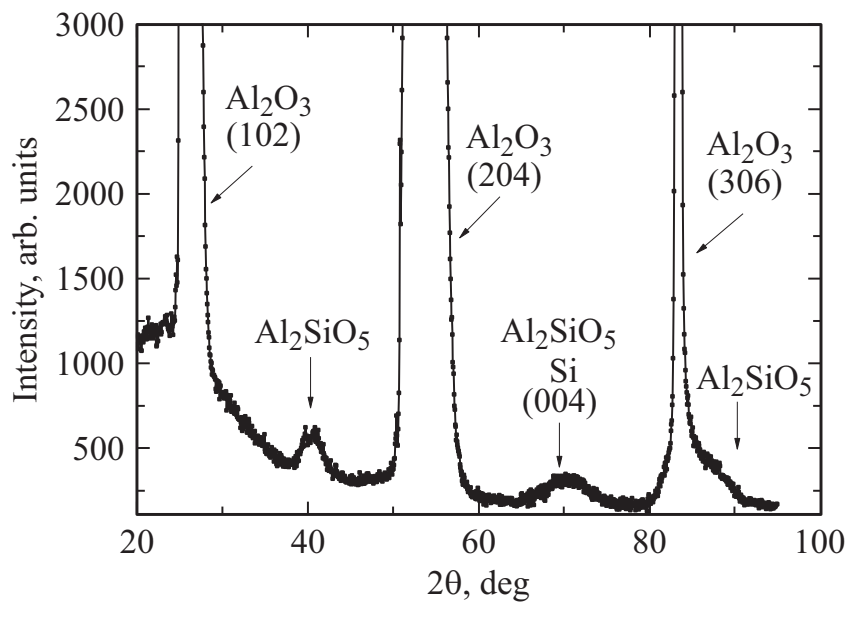

Рис. 2. Дифрактограмма сапфировой подложки, имплантированной дозой $2 \cdot 10^{16} \mathrm{~cm}^{-2}$.

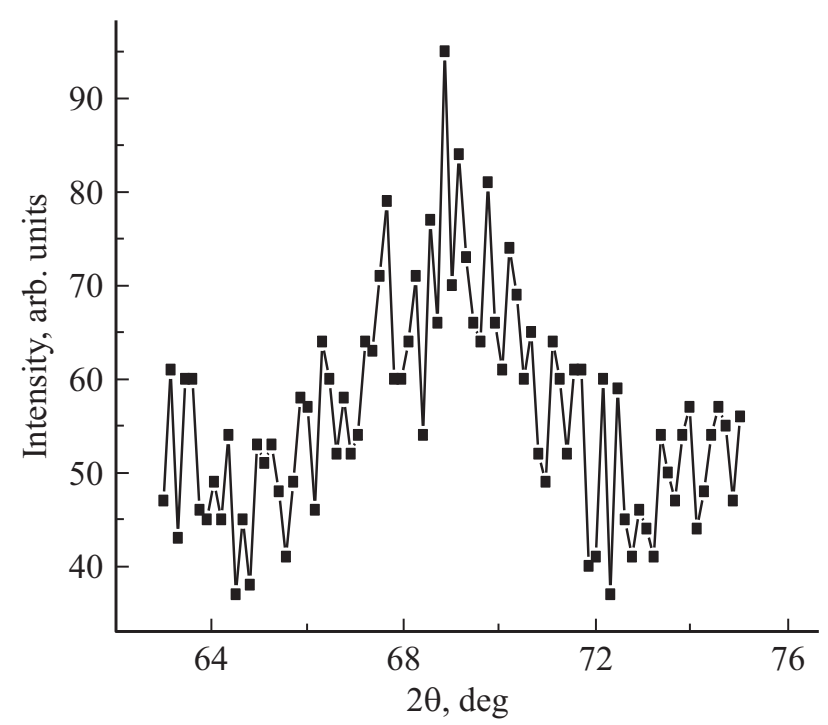

Рис. 3. Зависимость интенсивности отражения (400) $\mathrm{Si}$ от углового положения образца.

максимума $2 \theta=69^{\circ}$ (см. рис. 3). Исследование в других угловых диапазонах, связанных с $\mathrm{Si}$, не обнаружило дополнительных отражений, свидетельствуя о том, что часть первоначально изолированных атомов кремния после отжига объединяется в преципитаты $\mathrm{Si}$, причем наблюдаемые преципитаты кремния ориентированы вдоль направлений $\langle 100\rangle$. Подобные результаты наблюдались ранее при изучении люминесценции от сапфира после имплантации ионами кремния и высокотемпературного отжига [10].

Оценка минимальных размеров преципитатов проводилась по формуле Шеррера:

$$
d=k \lambda / \beta \cos \theta
$$

где $k=0.89$ - постоянная Шеррера, $\lambda=1.54 \AA-$ длина волны рентгеновского излучения, $\sim 3^{\circ}-$ ширина кривой качания на полувысоте (FWHM). 


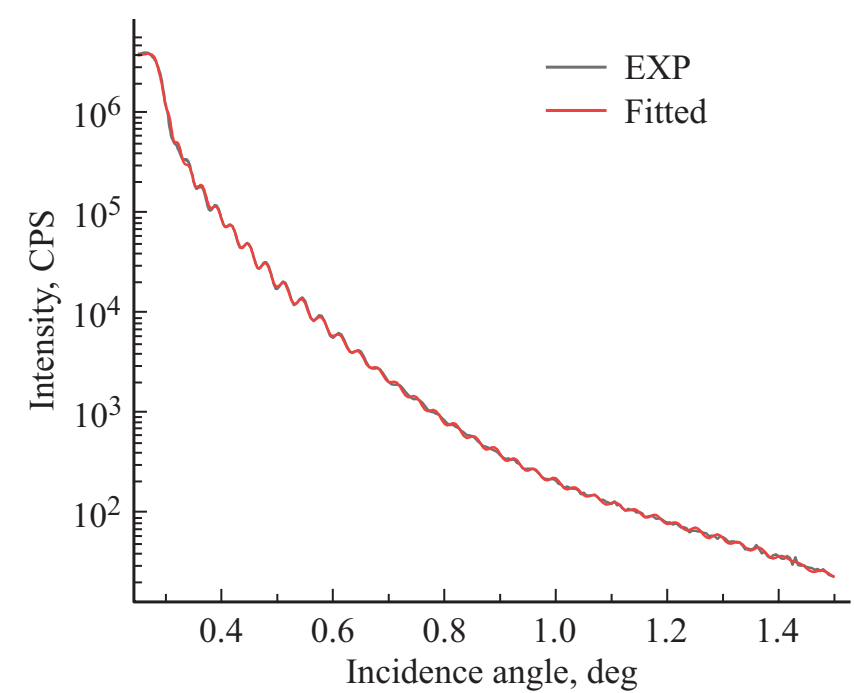

Рис. 4. Кривые ПВО: ЕХР - экспериментальная и Fitted расчетная.

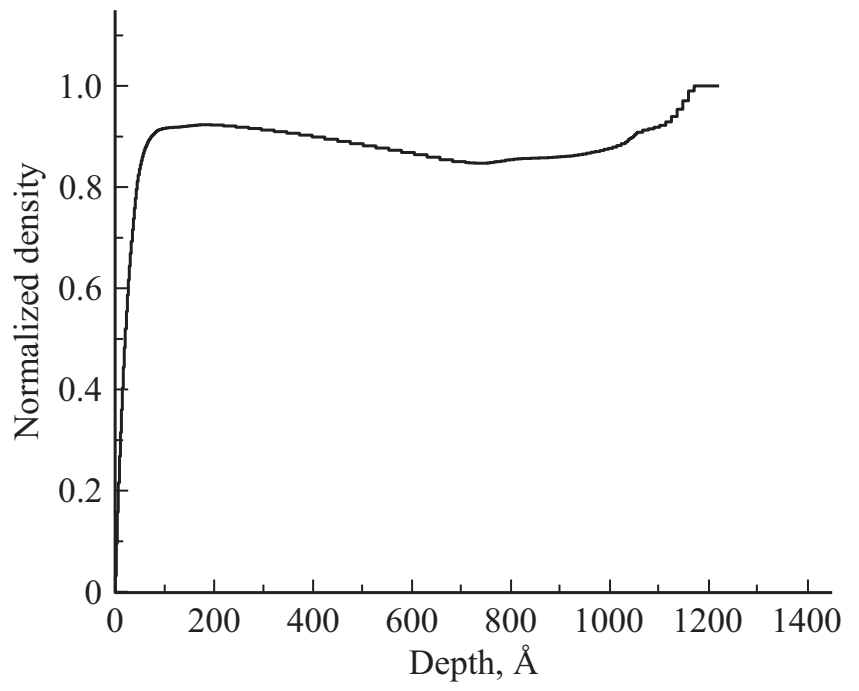

Рис. 5. Зависимость нормированной кривой плотности от глубины.

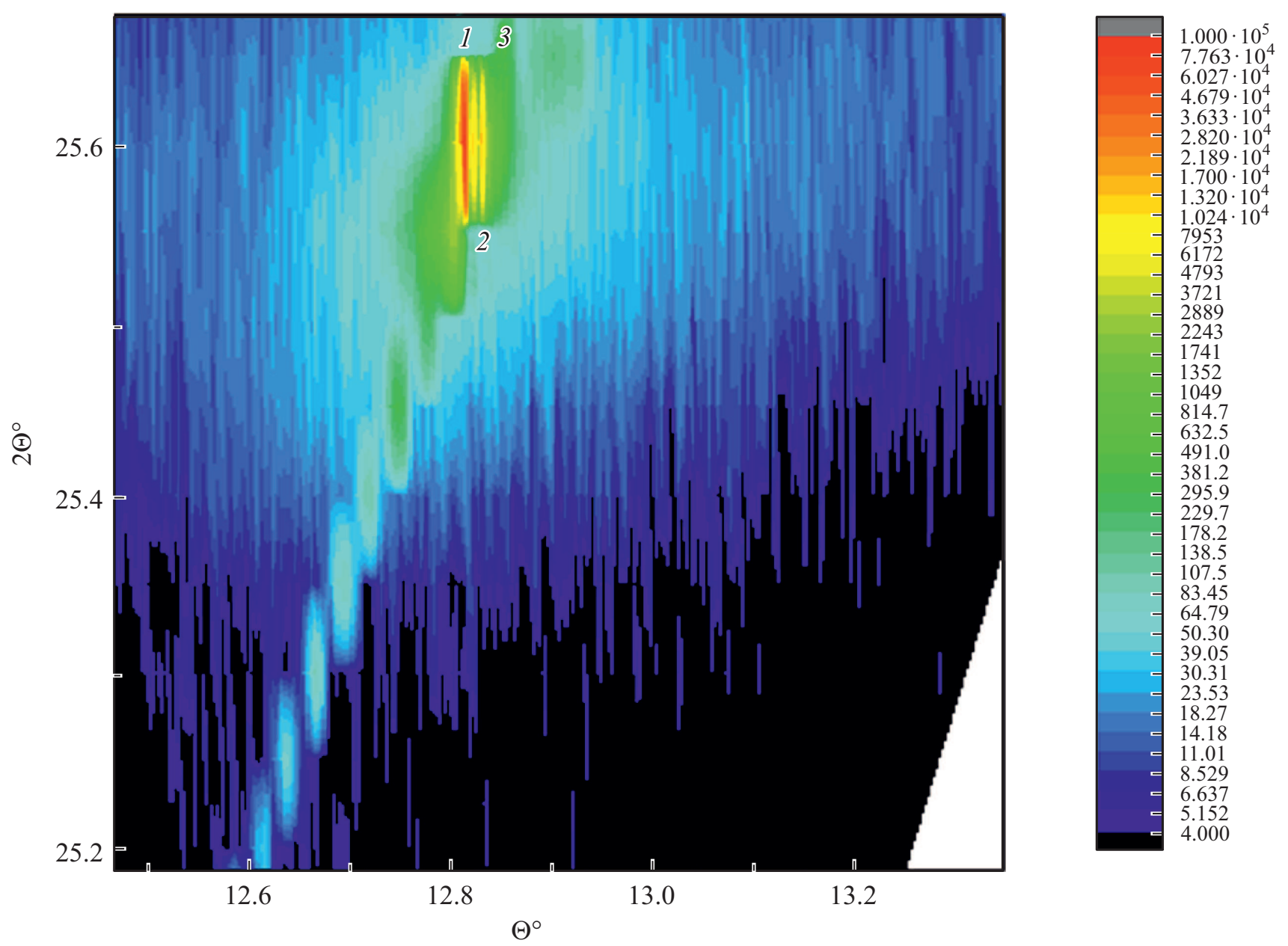

Рис. 6. Карта распределения дифракционной интенсивности в угловом пространстве, три дифракционных центра обозначены 1 , 2,3 . 
Наблюдаемый пик (400) соответствует преципитатам с минимальным размером частиц $\sim 3.2$ нм.

Другие наблюдаемые преципитатные образования скорее всего связаны с нанокристаллами компенсационного силиката $\mathrm{Al}_{2} \mathrm{SiO}_{5}$, для которого характерны отражения в районе углов $2 \theta=40,71,89^{\circ}$.

О расположении преципитатов в приповерхностной области сапфировой подложки можно судить по измерениям градиента плотности, проводимым на дифрактометре „Rigaku Smartlab“ рефлектометрическими методами (полное внешнее отражение - ПВО). Полученные данные приведены на рис. 4, кривая ПВО, а на рис. 5 - определенная по этим данным кривая зависимости плотности от глубины, нормированная на плотность сапфира. Наблюдаемый провал плотности на начальных нанометрах связан, по-видимому, с образованием в ходе технологического процесса разреженной пленки на поверхности сапфира.

Отличие рассчитанного профиля концентрации кремния и дефектов по программе TRIM от наблюдаемой экспериментальной кривой, возможно, связано с образованием дополнительных преципитатов алюмосиликата, что, как показано в работе [11], приводит к увеличению среднего проецированного пробега.

Дифракционные исследования возможных искажений сапфировой матрицы проводились методом RSM (измерения в обратном пространстве) для отражения (1102) на дифрактометре „Rigaku Smartlab“ с вращающимся анодом. Величина переданного импульса зависит от углов поворота образца $\omega$ и детектора $2 \theta$ следующим образом ( $x$ - направление нормали к поверхности, $y-$ в плоскости поверхности и дифракции):

$$
\begin{aligned}
& q_{y}=(4 \pi / \lambda) \sin \theta \sin (\omega-\theta), \\
& q_{x}=(4 \pi / \lambda) \sin \theta \cos (\omega-\theta) .
\end{aligned}
$$

Поэтому в случае $\omega=\theta$ сканирование в импульсном пространстве осуществляется вдоль нормали к поверхности образца.

Обнаружено три дифракционных центра (см. рис. 6): первый, соответствующий объемной дифракции сапфира с углом Брэгга $\theta_{\mathrm{B}}=12.788^{\circ}$ (обозначен как 1 на рис. 6), и два других, соответствующих сжатию в направлении, перпендикулярном поверхности, с различной долей интенсивности. Слабый максимум соответствует надпреципитатному слою с $\theta_{\mathrm{B}}=12.797^{\circ}$ (обозначен как 2 на pис. 6), а более интенсивный пик - слою с $\theta_{\mathrm{B}}=12.804^{\circ}$ (обозначен как 3 на рис. 6), что соответствует сжатию относительно объема на $0.12 \%$ и растяжению в $R$-плоскости на $0.2 \%$. Идентификация дифракционных пиков сапфира проводится по их яркости, цветом выделены области фиксированной интенсивности в соответствии с правой шкалой, приведенной на рис. 6. Штрихообразная форма центров связана с инструментальной функцией дифрактометра [12].

\section{4. Заключение}

Имплантация ионов кремния в пластину сапфира с $R$-плоскостной ориентацией и последующий высокотемпературный отжиг приводят к возникновению в приповерхностном слое ориентированных преципитатов как кремния с текстурой $\langle 100\rangle$, так и компенсационных нанокристаллических образований, возможно, связанных с образованием силиката $\mathrm{Al}_{2} \mathrm{SiO}_{5}$.

Отличия рассчитанного профиля концентрации кремния и дефектов по программе TRIM от рассчитанной по экспериментальным данным кривой концентрации плотности, возможно, объясняются образованием дополнительных преципитатов, наличие которых приводит к увеличению пробега.

В приповерхностной области сапфировой матрицы наблюдаются напряжения сжатия в направлении, перпендикулярном поверхности, приводящие к уменьшению параметра решетки на $0.12 \%$ и соответственно к напряжению растяжения в $R$-плоскости с увеличением параметра решетки на $0.2 \%$, что уменьшает несоответствие параметров решетки $R$-плоскости сапфира и кремния (100). Эпитаксиальное осаждение кремния на такую модифицированную сапфировую подложку должно привести к уменьшению дефектности кремниевого слоя КНС структуры.

\section{Финансирование работы}

Работа выполнена при поддержке Национального исследовательского центра „Курчатовский институт“ (приказ № 1575 от 16.07.2019).

\section{Конфликт интересов}

Авторы заявляют, что у них нет конфликта интересов.

\section{Список литературы}

[1] Y. Dong, M. Chen, J. Chen, X. Wang. J. Phys. D: Appl. Phys., 37, 1732 (2004).

[2] B. Aspar, M. Briel, H. Moricean et al. Microelectron. Eng., 36, 233 (1997).

[3] А.Е. Благов, А.Л. Васильев и др. Кристаллография, 59 (3), 356 (2014).

[4] M.I. Burgener, R.E. Reedy. Patent (USA), № 5.416.0.3. (1995).

[5] П.А. Александров, Н.Е. Белова, К.Д. Демаков, С.Г. Шемардов. ФТП, 49, 1124 (2015).

[6] П.А. Александров, К.Д. Демаков, С.Г. Шемардов. Патент 2581443 (РФ) / НИЦ „Курчатовский институт“ (2015).

[7] Ю.М. Чесноков, П.А. Александров, Н.Е. Белова, С.Г. Шемардов, А.Л. Васильев. Кристаллография, 62 (4), 613 (2017).

[8] П.А. Александров, К.Д. Демаков, С.Г. Шемардов, Н.Е. Белова. Поверхность. Рентгеновские, синхротронные и нейтронные исследования, № 8, 5 (2017). 
[9] П.А. Александров, К.Д. Демаков, С.Г. Шемардов, Ю.Ю. Кузнецов. Нано-микроскопическая техника, № 3, 54 (2008).

[10] R. Turan, S. Yerci, T.G. Finstad, S. Foss. ФTT, 51, 385 (2009).

[11] S. Yerci, I. Yildiz, M. Kulakci, U. Serincan, M. Barozzi, M. Bersani, R. Turan. J. Appl. Phys., 102, 024309 (2007).

[12] A. Mikhalychev, A. Benediktovitch, T. Ulyanenkova, A. Ulyanenkov. J. Appl. Cryst., 48, 679 (2015).

Редактор Л.В. Шаронова

\section{Implantation of silicon ions in sapphire: low doses}

\section{N.E. Belova, S.G. Shemardov, S.S. Fanchenko,} E.A. Golovkova, O.A. Kondratev

National Research Center „Kurchatov Institute“, 123182 Moscow, Russia

Abstract As a result of silicon ion implantation in sapphire and subsequent high-temperature annealing the precipitates of silicon and alumosilicates are observed in the subsurface sapphire region. $X$-ray reciprocal space mapping measurements showed existence of compression stress with deformation $-0.12 \%$ in the normal direction and tensile stress with deformation $0.2 \%$ in $R$-plane in that region, which reduces the mismatch with the silicon (100) lattice and can lead to improvement in the structural perfection of epitaxial silicon films grown on such modified sapphire substrates. 